\title{
Questionnaire Surveys of Cases of Tick Bite and Lyme Borreliosis in Hunters in Hokkaido with Reference to Detection of Anti-Borrelia burgdorferi Antibody
}

\author{
Nobuhiko Kubo, Yasutomo Arashima*, Minori Yoshida*, Masato Kawabata*, Susumu Nishinarita, \\ Takashi Hayama, Shigemasa Sawada, Takashi Horie, Minoru NaKao**, Kenji Miyamoto** and \\ Kinya Kawano*
}

\begin{abstract}
An epidemic of Lyme borreliosis on Hokkaido island, Japan, was surveyed by questionnaire in 587 hunters. The 308 returns $(\mathbf{5 2 . 4} \%)$ revealed episodes of tick bite (usually 2 or more) in $\mathbf{2 1 0}$ cases. Skin rashes appeared in 164 cases. Associated itching, pain, etc., but not skin rash, were more frequent after 2 or more tick bite. Previous determinations of anti-Borrelia burgdorferi antibody titers in these subjects and in controls suggested an association with outdoor activities other than hunting, and among 33 cases of dermatological symptoms and 23 of articular symptoms, 4 and 2 , respectively, were antibody-positive. Most of these antibody-positive subjects had suffered tick bite at least twice, but had had no antibiotic treatment. Three subjects with joint disorders were antibody-positive. These findings suggested that the many hunters exposed to Borrelia burgdorferi frequently carried latent infections, and that some had latent form of arthritis, dermatitis and other disorders.
\end{abstract}

(Internal Medicine 31: 1163-1168, 1992)

Key words: seroepidemiology, erythema chronicum migrans, arthralgia, arthritis

\section{Introduction}

Lyme borreliosis is a systemic infectious disease that is caused by the tickborne bacterium Borrelia burgdorferi; it is characterized by erythema chronicum migrans, various neurological symptoms, and a wide range of clinical signs such as chronic arthritis (1). In Japan, the first case of this condition was reported by Kawabata et al in 1987 (2), and reports followed of many cases in Nagano Prefecture and on the island of Hokkaido (3). Individuals in whom erythema chronicum migrans appeared after they received tick bites in Nagano and Hokkaido have been shown to be positive for the antiBorrelia burgdorferi antibody $(4,5)$, and not only have high rates of Borrelia spp. bacteria been isolated from both Ixodes ovatus and I. persulcatus ticks $(6,7)$, but also, in Hokkaido, they have been separated from erythematous tissues after the tick bite (8). Since Lyme borreliosis is transmitted by the bite of a tick that is host to Borrelia spp., data on the frequency of tick bites are important in the study of an epidemic of Lyme borreliosis. Yamaguchi stated that the majority of tick bites in Japan occur in Hokkaido and in the Tohoku region, and that most are due to $I$. ovatus and $I$. persulcatus (9). Miyamoto and Takahashi, after a survey of local forestry office employees in Hokkaido, noted that of 722 subjects, 483 $(66.9 \%)$ had experienced tick bites (10). In the past, before the existence of Lyme borreliosis became clear, scattered occurrences of erythema chronicum migrans following tick bites were reported in various parts of Japan. However, these bites were thought to cause only local symptoms; the few systemic symptoms that were observed were insignificant, and no associated chronic symptoms were found.

Since the ticks that are the vectors of this disease are found in the countryside, outdoor work and other outdoor activities may be considered risk factors. Nadal et al reported that many Swiss forestry workers were positive for anti-Borrelia burgdorferi antibodies, the higher rates of antibody-positive reaction being associated

From the First Department of Internal Medicine, Nihon University School of Medicine, *the Department of Clinical Pathology, Nihon University School of Medicine and **the Department of Parasitology, Asahikawa Medical College, Asahikawa

Received for publication November 25, 1991; Accepted for publication July 15, 1992

Reprint requests should be addressed to Dr. Nobuhiko Kubo, the First Department of Internal Medicine, Nihon University School of Medicine, 30-1 Oyaguchi-kamimachi, Itabashi-ku, Tokyo 173, Japan 


\section{Kubo et al}

with higher age groups and longer experience in such work (11). Also, Iguchi in Japan reported higher rates of the antibody (in comparison with control subjects) in Self-Defense Forces personnel in Hokkaido (12). In another controlled study, we found relatively high rates of antibody-positive reactions in the sera of Hokkaido hunters, and reported that one factor may be certain outdoor activities such as the gathering of wild plants (13). False-positive reactions for the antibody which are manifested in Lyme borreliosis sometimes appear in other infectious spirochetal diseases, and indeed, even in healthy subjects (14). Therefore, it is necessary in the interpretation of the results of determinations of antibody titers to arrive at an overall judgement based on such factors as the history of tick bite (if any) and the presence of erythema (if any). Accordingly, in the Hokkaido hunters previously examined for antibodies, we carried out questionnaire surveys on the occurrence of tick bite and on Lyme borreliosis. This report is intended to reveal tick bite information in Hokkaido hunters. Here, we discuss the possibility of the existence of chronic Lyme borreliosis in Japan on the basis of an analysis of the results of antibody determinations in the serum and analysis of questionnaires.

\section{Materials and Methods}

\section{Subjects}

The study was conducted in 587 hunters living in Hokkaido. They ranged in age from 26 to 74 years, 585 were men and 2 were women. After blood samples were drawn, the serum was stored at $-20^{\circ} \mathrm{C}$ until antibody determination was carried out.

\section{Questionnaire survey}

Questionnaire cards on tick bite and on Lyme borreliosis were distributed widely via the mail; the survey was conducted on the basis of those cards that were returned. Names were required on the questionnaires, which inquired about the occurrence of tick bites, the frequency, the month and place in which they occurred, systemic and local symptoms associated with tick bite and treatments received for the bites, diseases under current treatment, and so on.

\section{Determination of anti-Borrelia burgdorferi antibody titers}

For the determination of the serum levels of antiBorrelia burgdorferi antibody, the $3 \mathrm{M}$ IgG/IgM Fastlyme test (3M Diagnostic Inc.) (15) was carried out according to the instruction leaflet supplied with the testing kit. The serum was diluted with the diluent provided in the kit, and placed in wells coated with antigen. After incubation for 30 minutes, the wells were washed, and the enzymelabelled secondary antibody was reacted with the coating on the wells. These were then washed again, and after color development by the addition of a fluorescent matrix, the amount of fluorescence was measured. The number of fluorescence signal units obtained for each specimen was calculated as a percentage of the reference value (the number of fluorescence signal units for the reference serum in the kit), and this percentage was considered as an index of the antibody titer. The cut-off value, as specified in the kit leaflet, was taken to be $10 \%$ of the percentage of the reference value.

\section{Results}

\section{Questionnaire surveys on occurrence of tick bite}

The results of the questionnaire on the circumstances surrounding tick bites are shown in Table 1. A total of 308 questionnaires were returned by the hunters surveyed, representing a return rate of $52.4 \%$. Of these hunters, $210(68.2 \%)$ had suffered tick bites, 168 of them more than once. More tick bites occurred in June than in any other month, but the occurrence of the episodes extended from April to November, mostly in mountainous and bushy regions.

Table 2 presents the questionnaire results on the symptoms of tick bite. The highest concentration of tick bites on the head was on the ears, and those found on the trunk were mostly on the abdomen. Skin rashes appeared in 164 cases $(53.2 \%)$. General symptoms were seen after tick bite in four subjects $(1.3 \%)$ : fever alone

Table 1. Frequencies, Months and Geographical Locations of Tick Bites of Hunters in Hokkaido

$\begin{array}{lcc}\text { Frequency of tick bites } & & \\ & \text { Number of hunters } & \text { Rate (\%) } \\ \text { No tick bites } & 98 & (31.8) \\ \text { Onc or more tick bites } & 210 & (68.2) \\ \text { Bitten once } & 26 & \\ \text { Bitten more than once } & 168 & \\ \text { Frequency uncertain } & 16 & \end{array}$

Time of tick bites

$\begin{array}{lcc} & \text { Number of episodes* } & \text { Rate }(\%) \\ \text { April } & 11 & (2.9) \\ \text { May } & 107 & (28.1) \\ \text { June } & 145 & (38.1) \\ \text { July } & 68 & (17.9) \\ \text { August } & 26 & (6.8) \\ \text { Scptember } & 12 & (3.2) \\ \text { October } & 10 & (2.7) \\ \text { November } & 1 & (0.3)\end{array}$

Location of episodes

Mountain

Bush

Forest

Field

Hill

$\begin{array}{cc}\text { Number of cpisodes* } & \text { Rate }(\%) \\ 110 & (35.4) \\ 79 & (25.4) \\ 70 & (22.5) \\ 49 & (15.8) \\ 3 & (0.9)\end{array}$

* In cases where the same subject was bitten more than once, each cpisode was added separately to the total. 
Tick Bite and Lyme Borreliosis in Hokkaido

Table 2. Parts of Body Affected, and Symptoms Caused by Tick Bites

\begin{tabular}{lrr}
\hline & Number of episodes & Rate (\%) \\
Part of body affected & 127 & $(28.1)$ \\
Head & 61 & \\
Scalp & 14 & \\
Face & 7 & \\
Neck & 45 & $(53.3)$ \\
Ear & 241 & \\
Trunk & 29 & \\
Shoulder & 4 & \\
Axilla & 50 & \\
Chest & 30 & \\
Back & 111 & \\
Abdomen & 5 & \\
Pelvic region & 12 & \\
Genitals & & \\
Extremities & & \\
Upper & 54 & $(18.6)$ \\
Lower & 30 & $(7.5)$ \\
Post-tick bite skin rash & & \\
Present & & \\
Absent & 164 & \\
Uncertain & & \\
Post-tick bite symptoms & & \\
Present & & \\
Absent & & \\
\hline
\end{tabular}

* The symptoms seen in four respective cases were: fever alone; fever and general fatigue; fever, arthralgia and lymphadenitis; and arthralgia and general fatigue.

in one; fever and general fatigue in another; fever, arthralgia and lymphadenitis in the third; and arthralgia and general fatigue in the last.

The elapse time before the removal of the tick after a bite are listed in Table 3, together with the numbers of cases treated and not treated with antibiotics. In $8.4 \%$ of cases, the removal was immediate, and in most cases the ticks were removed within a day, but sometimes longer periods elapsed before this was done. Only 6 of the subjects $(1.9 \%)$ received antibiotic treatment.

Local symptoms associated with tick bites, and frequency of bites

The following local symptoms occurred after tick bites, with the numbers of cases shown: itching (122 cases), pain (64 cases), and both itching and pain (12 cases); and in another 12 episodes, no such symptoms were observed. A tendency was recognized for local symptoms to occur with a much higher frequency in subjects who had been bitten at least twice. All 4 hunters who had general symptoms had been bitten more than once (Table 4).

Appearance of tick bite-associated skin rashes in relation to frequency of tick bites

The results of the examination of tick bite-associated
Table 3. Elapsed Time before Removal of Tick, and Antibiotic Treatment of Tick Bites

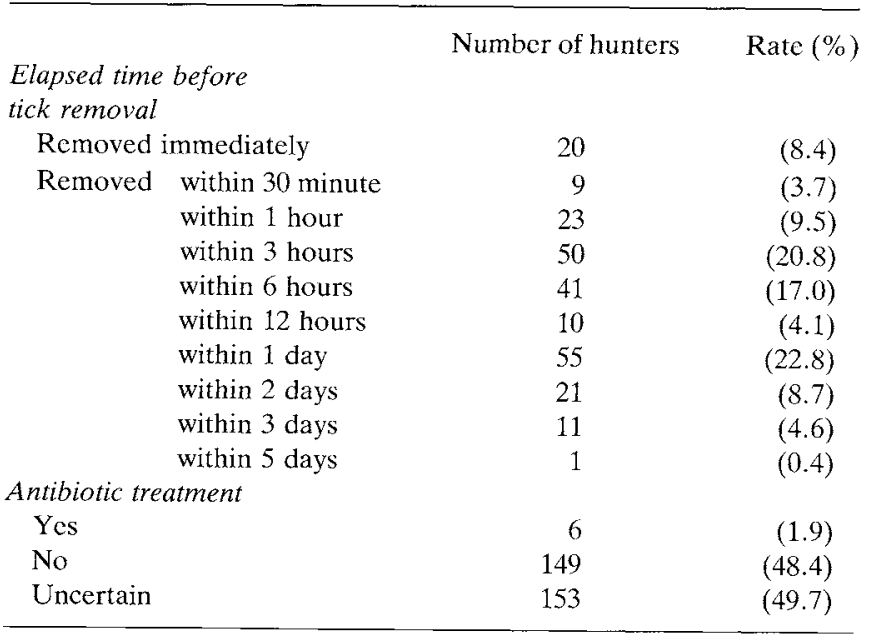

Table 4. Types of Symptoms by Frequency of Tick Bites

\begin{tabular}{lccc}
\hline & \multicolumn{3}{c}{ Tick bite frequency (Number of hunters) } \\
Symptom & Once & More than once & Not known \\
Local symptoms & & & \\
Itching $(\mathrm{n}=122)$ & 11 & 98 & 13 \\
Pain $(\mathrm{n}=64)$ & 3 & 58 & 3 \\
Itching and Pain $(\mathrm{n}=12)$ & 1 & 11 & 0 \\
General symptoms & 0 & 4 & 0 \\
$\quad(\mathrm{n}=4)$ & & 3 & 4 \\
No symptoms $(\mathrm{n}=12)$ & 5 & & \\
\hline
\end{tabular}

Tablc 5. Occurrence of Skin Rashes by Frequency

\begin{tabular}{lccc}
\hline & \multicolumn{3}{c}{ Tick bite frcquency (Number ổ hunters) } \\
Occurrence of skin rash & Once & More than once & Not known \\
Occurred & 11 & 104 & 11 \\
No skin rash & 9 & 96 & 3 \\
\hline
\end{tabular}

skin rashes and the frequency of tick bites are given in Table 5. Skin rashes occurred in approximately one-half of the cases of tick bite, but, unlike the local symptoms, exhibited no tendency of correlation with the frequency of the bites.

In Table 6 are shown the chronic symptoms in relation to the antibody. Cases of some type of dermatological symptoms, arthrological symptoms, and both numbered 24,14 , and 9, respectively. Almost all of these symptoms appeared in hunters who had suffered more than one tick bite and had not received any antibiotic treatment. Similarly, antibody-positive subjects had almost all been bitten twice or more times and had not been administered any antibiotics.

Table 7 lists the types of complications or symptoms, together with the distribution of antibody-positive cases, found amongst those hunters currently under medical 


\section{Kubo et al}

Table 6. Relationship of Frequency of Tick Bites and Administration of Antibiotics to Skin and Joint Symptoms in Hunters

\begin{tabular}{|c|c|c|c|c|c|c|c|c|}
\hline & \multicolumn{4}{|c|}{ Tick bite frequency* } & \multicolumn{4}{|c|}{ Antibiotics administration* } \\
\hline & Once & $\begin{array}{l}\text { More than } \\
\text { once }\end{array}$ & $\begin{array}{c}\text { Not } \\
\text { known }\end{array}$ & None & Yes & No & $\begin{array}{l}\text { Do not } \\
\text { recall }\end{array}$ & $\begin{array}{l}\text { No } \\
\text { choice }\end{array}$ \\
\hline Skin $\operatorname{rash}(n=24)$ & $\begin{array}{c}2 \\
(1)\end{array}$ & $\begin{array}{l}21 \\
(3)\end{array}$ & 0 & 1 & 1 & $\begin{array}{l}19 \\
(4)\end{array}$ & 0 & 3 \\
\hline Arthralgia $(\mathrm{n}=14)$ & 0 & $\begin{array}{c}8 \\
(1)\end{array}$ & 1 & $\begin{array}{c}5 \\
(1)\end{array}$ & 0 & $\begin{array}{c}9 \\
(1)\end{array}$ & 0 & 0 \\
\hline $\begin{array}{l}\text { Skin rash and } \\
\text { arthralgia }(n=9)\end{array}$ & 0 & 8 & 0 & 1 & 1 & 5 & 1 & 1 \\
\hline
\end{tabular}

* Number of hunters/(Number of antibody-positive cases).

Table 7. Complications or Symptoms of 308 Hunters Surveyed by Questionnaire

\begin{tabular}{|c|c|c|c|}
\hline & $\begin{array}{l}\text { Complication or } \\
\text { symptom number }\end{array}$ & Incidence $(\%)$ & $\begin{array}{l}\text { No. of antibody- } \\
\text { positive hunters }\end{array}$ \\
\hline \multicolumn{4}{|c|}{ Joint or muscular disorders } \\
\hline Arthralgia & 3 & 1.0 & 2 \\
\hline Gout & 2 & 0.6 & \\
\hline Frozen shoulder & 1 & 0.3 & \\
\hline Lumbago & 1 & 0.3 & \\
\hline Rheumatism & 1 & 0.3 & 1 \\
\hline Fibromyalgia & 1 & 0.3 & \\
\hline \multicolumn{4}{|l|}{ Neurological disorders } \\
\hline Vibration disease & 2 & 0.6 & \\
\hline Parkinsonism & 1 & 0.3 & \\
\hline Facial nerve pulsy & 1 & 0.3 & \\
\hline Neuralgia & 1 & 0.3 & \\
\hline Headache & 1 & 0.3 & \\
\hline Others & 3 & 1.0 & \\
\hline \multicolumn{4}{|l|}{ Cardiovascular disease } \\
\hline Hypertension & 8 & 2.6 & 2 \\
\hline Heart discase & 6 & 1.6 & 1 \\
\hline Angina pectoris & 1 & 0.3 & \\
\hline Sick sinus syndrome & 1 & 0.3 & \\
\hline \multicolumn{4}{|l|}{ Other conditions } \\
\hline Diabetes mellitus & 8 & 2.6 & \\
\hline Peptic ulcer & 6 & 1.9 & \\
\hline Hepatic disease & 3 & 1.0 & 1 \\
\hline Asthma or bronchitis & 3 & 1.0 & \\
\hline Renal disease & 1 & 0.3 & \\
\hline Polycythemia & $i$ & 0.3 & \\
\hline Allergy & 1 & 0.3 & \\
\hline Bone fracture & 1 & 0.3 & \\
\hline Traffic accident & 1 & 0.3 & \\
\hline
\end{tabular}

treatment. There were few ( 7 cases) antibody-positive subjects who were under treatment, but three antibodypositive hunters were found among those with articular disorders.

\section{Discussion}

We have already reported that the population of cases that are seropositive for anti-Borrelia burgdorferi antibody among hunters in Hokkaido is higher than that in a control population, and that one possible contributory factor lies in outdoor activities such as the gathering of wild plants in the mountains (13). A tendency was noted for many antibody-positive cases to be in older age brackets, but no correlation was seen with the length of hunting experience. In addition, that report indicated that the correlation between the antibody titer, on the one hand, and the tick bite and clinical symptoms, on the other, was not clear. It is necessary in interpreting a seropositive reaction for the Borrelia 
burgdorferi antibody as indicating Lyme borreliosis, to take into account the clinical findings, such as the appearance of a skin rash. For these reasons, we distributed questionnaire surveys on tick bite and Lyme borreliosis to these hunters. The results showed that tick bites had occurred in a considerable number of hunters, the majority between May and July. A survey of local forestry office employees in Hokkaido by Miyamoto and Takahashi found that $483(66.9 \%)$ of the 722 subjects covered reported that they had been bitten by ticks, and that most of these tick bite episodes had occurred in June and July (10). In the present study, the frequency and timing of the majority of tick bite episodes were almost the same as these.

Since the present survey was carried out by questionnaire, there were methodological limitations to its accuracy. The low return rate of the mailed questionnaires, $52.4 \%$, could be the source of some bias in the conclusions. Nevertheless, our discussion of the proportion of hunters bitten by ticks may have validity within these limits. In any event, the animals that are the prey of these hunters are frequently infested with ticks, and so these people are more capable than most of recognizing and identifying a tick, and their answers to questions about tick bites are more likely than those of the ordinary man-in-the-street to yield correct and accurate results to such a survey. In addition, the high proportion of hunters investigated who had a history of tick bite, 210 out of 587 , or $35.8 \%$, indicated that the chances of suffering a tick bite are substantial.

Before the existence of Lyme borreliosis was confirmed, erythema chronicum migrans arising after a tick bite had been reported in various regions of Japan (1619). However, since it was thought that tick bite caused only local symptoms, and that the few systemic symptoms that were seen were insignificant, no associated chronic symptoms have until now been recognized (9). The initial symptoms of Lyme borreliosis are non-specific cold-like symptoms such as fatigue, headache, fever, local lymph node swelling, wandering muscle pains, and arthralgia (1), and it is possible that the relationship with tick bite is often not realized. Tick bites are found on all regions of the body, and the time that elapsed after the discovery of a bite until the tick was removed was shown by the survey to be very short (indicating immediate removal) in only $8.4 \%$ of cases, whereas in all other cases there was ample time for the infection to be transmitted. It has been reported after animal experiments that infection takes place in $7.1 \%$ of animals after the tick has adhered to the body for 24 hours, in $35.7 \%$ after 48 hours, and in $92.9 \%$ after 72 hours (20). In Hokkaido, Borrelia spp. have been isolated from ticks (6) and from erythematous tissue (7). The main species of ticks by which humans are bitten in Hokkaido are $I$. ovatus and I. persulcatus, and Borrelia spp. have been isolated from a high proportion of ticks of both types. Consequently, from the results of the present questionnaire surveys, it can be considered that many of the hunters have been exposed to these bacteria. In comparison with those bitten only once, subjects who had more than one bite were found to have a higher frequency of local pain and itching and dermatological findings. On the other hand, no tendency toward a correlation between the occurrence of skin rashes and the frequency of tick bites was observed. This suggests the possibility that some other causative factor may be involved in the local symptoms and dermatological findings. Tick bite is known to be accompanied with such symptoms as irritation and pain (9), but a large number of factors, such as mite allergies, the immune response to saliva, the effect of other bacteria that may coexist with Borrelia spp., and a predisposition in the host, contribute to the appearance of dermatological symptoms. The characteristic skin rash of Lyme borreliosis, erythema chronicum migrans, is not generally thought to be accompanied by itching or pain, but the definition of this condition is not always clear. Through the survey of chronic symptoms and the investigation of antibody, antibody-positive individuals were found among those showing some type of chronic dermatological and arthrological symptoms.

False-positive reactions to the antibody that is manifested in Lyme borreliosis sometimes appear in other infectious spirochetal diseases, and also sometimes in healthy subjects (14) and in patients with various rheumatic diseases (21). The majority of antibodypositive subjects had not undergone antibiotic treatment for tick bite, and had been bitten more than once. For this reason, the antibody titer was thought to be an indicator that the subject had been infected through a tick bite. However, it is difficult to judge whether individual hunters actually had Lyme borreliosis, and this question must be approached with care because a diagnosis of Lyme borreliosis must be confirmed by a competent physician who has examined the symptoms. Moreover, the antibody assay method used in this study has been reported to have a specificity of $94.5 \%$ in the syphilis-negative blood serum of Japanese subjects (14). The serum antibody titers have to be considered and an overall evaluation must be made in conjunction with questions such as whether the tick bite episode was in an epidemic region, how much time had elapsed since the bite, and whether a skin rash was present, before a definite diagnosis can be given. False negatives are seen in the early stage of an infection, and are reported as seronegative Lyme borreliosis.

Through examination of the relationship of the disorders under treatment at the time of the questionnaire survey and the antibody, three antibody-positive subjects with joint diseases were identified. Those surveyed were middle-aged to elderly, and can therefore be considered to have been at ages favored by other chronic skin and joint disorders. In every case, increased circumspection 
is necessary in the differential diagnosis between Lyme borreliosis and other diseases. However, as has already been pointed out, because, as a group, these hunters were seen to have received a considerable number of tick bites, which were followed by skin rashes (possibly including erythema or erythema migrans), and because many antibody-positive subjects were found among them, the likelihood of the presence of chronic latent Lyme borreliosis infections among them is thought to be high. Two reports have already appeared on the subject of anti-Borrelia burgdorferi antibody-positive cases in Hokkaido manifesting post-tick bite erythema and articular symptoms after tick bite $(22,23)$, but in Japan, there are as yet no reports of the occurrence of dermatological lesions of acrodermatitis chronica atrophicans in the chronic stage of Lyme borreliosis. We believe that it is now necessary for clinicians treating diseases in patients from Hokkaido to be reminded of the possibility of Lyme borreliosis.

Acknowledgements: The authors wish to express thcir thanks to Ms. M. Mori, the staff of Asahikawa Medical College, and Mr. Y. Yamanaka, a student at the same college, for their work in dispatching and collecting the questionnaire cards, and to Mr. C.W.P. Raynolds for valuable advice and assistance in preparing this manuscript.

\section{References}

1) Steere AC. Lyme disease. N Engl J Med 321: 586, 1989.

2) Kawabata $M$, Baba $S$, Iguchi $K$, et al. Lyme disease in Japan and its possible incriminated tick vector, Ixodes persulcatus. J Infect Dis 156: 854, 1987.

3) Sasa Y, Kawabata M, Iguchi K, ct al. Case report of Lyme disease showing large erythematous lesion in the abdomen. J J A Inf D 62: 500, 1988 (English abstract).

4) Iguchi K, Kawabata M, Arashima $Y$, et al. Studies on 15 seropositive cases of Lyme disease using immunoperoxidase test in Japan. J J A Inf Dis 65: 527, 1990 (English abstract).

5) Kubo N, Arashima Y, Yoshida M, et al. Detection of anti-Borrelia burgdorferi antibodies in six patients with crythema chronicum migrans after tick bite in Japan. Igakunoayumi 153: 701, 1990 (English abstract).

6) Miyamoto K, Nakao M, Sato N, et al. Isolation of Lyme disease sporochetes from an ixodid tick in Hokkaido, Japan. Acta Tropica 49: 65, 1991.

7) Miyamoto K, Nakao M. Epidemiology of Lyme borreliosis. Kansen ensyo men'eki 21: 69, 1991 (in Japanese).

8) Kawagishi N, Hashimoto $Y$, Matsuo S, et al. 2 cases of Lyme borreliosis with successful isolation of Borrelia burgdorferi. Abstract of the 297th conference of the Hokkaido Branch of the Japanese Association for Dermatology, 1989 (in Japanese).

9) Yamaguchi N. Human tick bite: Variety of tick species and increase of cases. Saishin Igaku 44: 903, 1981 (English abstract).

10) Miyamoto K, Takahashi K. Human ixodiasis in Hokkaido: Case report and questionnaire for the forestry organization. Jpn J Sanit Zool 41: 59, 1990.

11) Nadal D, Wunderli $W$, Briner $H$, et al. Prevalence of antibodies to Borrelia burgdorferi in forestry workers and blood donors from the same region in Switzerland. Eur J Clin Microbiol Infect Dis 8: 992, 1989.

12) Iguchi K. Studies of a serological test for Lyme disease and its application to epidemiological surveys. J Nihon Univ Mcd Ass 47: 955, 1988 (English abstract).

13) Kubo N, Arashima Y, Kawabata M, ct al. Study of anti Borrelia burgdorferi antibody of hunters in Hokkaido. J J A Inf D 66: 45, 1992 (English abstract).

14) Magnarelli LA, Anderson JF, Johnson RC. Crossreactivity in serological tests for Lyme disease and other spirochetal infections. J Infect Dis 156: 183, 1989.

15) Kubo N, Arashima Y, Kumasaka K, et al. Detection of anti Borrelia burgdorferi antibody by using $3 \mathrm{M} \mathrm{IgG} / \mathrm{IgM}$ FASTLYME test. Kikishiyaku 13: 504, 1990 (in Japanese).

16) Shiratori A, Shimazaki T. A case of erythema chronicum migrans. Acta Dermatol (Kyoto) 62: 258, 1967 (in Japanesc).

17) Sudoh M, Isyu M, Takishima 1 . Erythema chronicum migrans. rinsho derma (Tokyo) 20: 515, 1987 (in Japanese).

18) Okabe S. Erythema chronicum migrans and erythema papulatum centrifugum. rinsho derma (Tokyo) 22: 135, 1980 (in Japanese).

19) Tohgi K, Sugihara K, Jidoi J. Two cases of erythema chronicum migrans. Nishinihon J Dermatol 49: 45, 1989 (in Japanesc).

20) Piesman J, Mather TN, Sinsky RJ, et al. Duration of tick attachment and Borrelia burgdorferi transmission. J Clin Microbiol 25: 557, 1987.

21) Kawabata $K$, Kubo N, Arashima $Y$, et al. Effect of autoantibodies on scrological tests for Lyme borreliosis. Jpn J Clin Pathol 38 (suppl): 114, 1991 (in Japanese).

22) Hashimoto $Y$, Mizumoto $T$, Ookuma $N$, ct al. A case of Lyme discase. Rinsho Hifuka 43: 1101, 1989 (in Japanese).

23) Kubo N, Arashima $Y$, Yoshida M, et al. Case report of Lyme borreliosis. Biomedicine \& Therapeutics 25: 245, 1991 (in Japanese). 